\title{
Suicidal Behavior and the Serotonin Transporter Gene Polymorphism (5-HTTLPR) with Novel Subtypes, in Danish Schizophrenic Patients
}

\author{
August G. Wang ${ }^{*}$,, Henrik B. Rasmussen ${ }^{\mathrm{b}}$, Holger J. Sørensen ${ }^{\mathrm{a}}$, Marianne Hvid ${ }^{\mathrm{a}}$, Claus Breddam ${ }^{\mathrm{a}}$, \\ Bjarne Hansen $^{\mathrm{a}}$, Vibeke Høg Bille ${ }^{\mathrm{a}}$, Ole Garsdal ${ }^{\mathrm{a}}$, Anne Sophie Jacoby ${ }^{\mathrm{a}}$, Karen Søeby ${ }^{\mathrm{b}}$, \\ Henrik Dam $^{\mathrm{c}}$, Lasse Krogsbøll ${ }^{\mathrm{d}}$, Sally Timm ${ }^{\mathrm{d}}$ and Thomas Werge ${ }^{\mathrm{b}}$ \\ ${ }^{a}$ University Department of Psychiatry, H:S Amager Hospital, DK-2300 Copenhagen, Denmark \\ ${ }^{b}$ Research Institute of Biological Psychiatry, H:S Sct. Hans Hospital, DK-4000 Roskilde, Denmark \\ ${ }^{c}$ University Department of Psychiatry, H:S Rigshospitalet, DK-2100 Copenhagen, Denmark \\ ${ }^{d}$ University Department of Psychiatry, H:S Frederiksberg Hospital, DK-2000 Frederiksberg, Denmark
}

\begin{abstract}
Background: Literature reports a genetic component for suicidal behavior, especially of determinant/violent type. One of the candidates has been the polymorphism 5-HTTLPR in the serotonin promoter. Employing a between group design, we wished to test the association between suicidal behavior and serotonin-related polymorphisms.

Method: 350 Danish patients with average 14 years' duration of illness and with well researched history of suicidal behavior participated. Three groups were identified: 1. without suicidal behavior, 2. with suicidal behavior of nondeterminant/non-violent methods, and 3. suicidal behavior with determinant/violent methods. We used the common alleles $\mathrm{S}$ and $\mathrm{L}$ as well as the new aspect with allelic subtypes $\mathrm{S}_{\mathrm{A}}, \mathrm{S}_{\mathrm{G}}, \mathrm{L}_{\mathrm{A}} \cdot \mathrm{L}_{\mathrm{G}}$ to constitute 3 functional genotypes: SS, SL and LL. We also included duration of illness, age at onset and sex in our study as potential covariates.

Results: We tested suicidal behavior types 2 and 3 versus type 1 for distribution differences as well as for possible trend. We did not find any statistical significant relations.

Conclusions: We could not find support for a relevant relation between the polymorphisms in the serotonin promoter and suicidal behavior in our schizophrenic patient sample.
\end{abstract}

Keywords: Suicidal behavior, genetics, schizophrenia, serotonin transporter.

\section{INTRODUCTION}

Psychiatric disorders, such as schizophrenia [1] are wellknown risk factors for suicidal behavior. Whether the causes of suicide are identical in different psychiatric diseases is unknown, but suicidal behavior is known to be particularly frequent at certain stages of each disorders. In schizophrenia most suicides occur within the first years after the onset of disease $[2,3]$.

There is evidence that suicidal behavior is influenced by biological and genetic factors, especially suicidal behavior by violent /determinant means [4-6]. Of importance, this form of suicidal behavior has been associated with low concentrations of the serotonin metabolite 5-HIAA in the cerebrospinal fluid [7]. Several studies have attempted to identify genes involved in suicidal behavior in psychiatric disorders, with particular focus on the role of the serotonergic pathway in affective disorders [8-11]. In a recent meta-analysis, the authors found association between variations in the 5-HTT gene (serotonin transporter gene) and suicidal behavior in general [12]. To date, only a limited

*Address correspondence to this author at the University Department of Psychiatry, H:S Amager Hospital, DK-2300 Copenhagen, Denmark; E-mail: agwang@get2net.dk number of studies have been conducted with the aim of identifying genetic risk factors of suicidality in schizophrenia, and they rarely distinguish between different forms of suicidal behavior [13]. However, it is likely that the 5 -HTT gene is associated with violent, as opposed to nonviolent, suicidal behaviors. For example, Bayle et al. reported an association between violent suicidal behavior among schizophrenic patients and the polymorphism designated 5-HTTLPR in the promoter of the gene encoding for the serotonin (5-hydroxytryptamine, 5-HTT) transporter SERT [5]. The serotonin transporter gene is located on chromosome 17. This gene has a polymorphic repetitive element, 5-HTTLPR, with two common alleles, designated " $\mathrm{L}$ " for long or " $\mathrm{S}$ " for short. The uptake of $5-\mathrm{HT}$ is approximately two-fold higher in cells containing the homozygous LL form [10]. As a new aspect, a single nucleotide polymorphism, $r s 25531(\mathrm{~A}>\mathrm{G})$, in one of the repetitive elements of 5-HTTLPR leads to the appearance of the allelic subtypes designated $S_{A}, S_{G}, L_{A}$ and $L_{G}$ [14-16]. Of these alleles $S_{A}, L_{A}$ and $L_{G}$ are common among Caucasians while $S_{G}$ is a rare allele. Applying this new knowledge, a replication study could not confirm the findings by Bayle et al. [6]. 
Based on the potential link between lower levels of 5HTT and suicidal behavior, we hypothesized that genotypes with the $\mathrm{S}$ allele would show an association with lifetime suicidal behavior types more specifically than the SS genotype would show a special relation to the violent/determinant type of lifetime suicidal behavior. Also we would include the new aspect of the allelic subtypes.

\section{MATERIALS AND METHODS}

\section{Sample}

A total of 350 schizophrenic patients were included in the study. Patients had previously been recruited to the Danish Psychiatric Biobank from six psychiatric hospitals and centers in the Copenhagen area. All patients were ethnically Caucasians and Danes, i.e. the patient and both parents were born in Denmark. Baseline data were obtained on sex, age at onset (defined as age at first psychiatric contact) and illness duration (defined as recruitment age minus age at onset).

\section{Diagnosis and Phenotypic Rating}

All patients were diagnosed as having schizophrenia (F20) according to ICD-10 Research Criteria. The reliability of the clinical diagnosis was confirmed by a semi-structured interview using the OPCRIT instrument by an experienced consultant psychiatrist [17]. Comprehensive lifetime clinical data and socio-demographic information were collected from medical records covering numerous hospital admissions and through interviews with patients and medical staff. Suicidal behavior was scored in an operational manner and distinction was made to rate suicidal intent, which has proven unreliable [18]. Patients were classified into the following categories: Type 1: no suicidal behavior, Type 2: suicidal behavior without violent means, and Type 3 suicidal behavior with violent/determinant means [4,5]. Type 2 and Type 3 patient groups were separately compared with the Type 1 patient group. We also combined Types 1 and 2 groups in order to contrast them with the Type 3 group.

\section{Genotyping}

Genotyping of 5-HTTLPR including $r s 25531$ was done using a novel procedure which permits detection of all the major alleles, namely $S_{A}, L_{A}$ and $L_{G}$, in addition to $S_{G}$ [19]. Analysis of 5-HTTLPR sequences by the NEBcutter V2.0 program revealed that digestion with NeiI would allow determination of all major alleles in addition to some of the rare alleles. Using this program we also found that digestion with NlaIII in a separate reaction could improve the ability to discriminate the $\mathrm{S}_{\mathrm{G}}$ alleles 14-B and 14-D from 16-D $\left(\mathrm{L}_{\mathrm{G}}\right)$ and permit identification of the rare 14-C allele. Consequently, we used both restriction enzymes. Amplified products in volumes of $25 \mu \mathrm{l}$ were mixed with $2.5 \mu \mathrm{l}$ of $10 \mathrm{x}$ restriction enzyme buffer $(200 \mathrm{mmol} / \mathrm{l}$ Tris-acetate, 500 $\mathrm{mmol} / 1$ potassium acetate, $100 \mathrm{mmol} / \mathrm{l}$ magnesium acetate, $10 \mathrm{mmol} / 1$ dithiothreitol, $\mathrm{pH} 7.9$ ) and $0.25 \mu \mathrm{l}$ of $10 \mathrm{mg} / \mathrm{ml}$ bovine serum albumin. Subsequently, this mixture was divided into two portions of equal volumes. To the first of these two portions we added 10 units of NeiI; 5 units of NlaIII were added to the other. Both digestion mixtures were incubated overnight at $37^{\circ} \mathrm{C}$. Fragments of DNAS were subjected to electrophoresis in gels composed of 3.5\% MetaPhor (Cambrex Bio Science Rockland Inc., Rockland, Maine, USA) and stained with ethidium bromide.

The short allele (S) predicts lower levels of 5-HTT and HTT activity in vitro. The long $G$ and long $A$ alleles are functionally distinct, so the $\mathrm{G}$ nucleotide is more similar to the short (S) variant [20]. In this study, the long variant $G$ and the short variant $(\mathrm{S})$ are therefore grouped together and designated $\mathrm{S}$, while $\mathrm{L}_{\mathrm{A}}$ is designated $\mathrm{L}$.

In addition to the three major alleles, $\mathrm{S}_{\mathrm{A}}$ (14 repeat units), $\mathrm{L}_{\mathrm{A}}$ and $\mathrm{L}_{\mathrm{G}}$ (both composed of 16 repeat units) a longer variant composed of 21 repeat units was detected. We classified the latter as $\mathrm{L}$.

\section{Risk Factors}

We considered that the schizophrenia was the precipitating factor and the duration of schizophrenic illness was the risk period. The genotypes LL, LS and SS were risk factors, and sex and age at onset were studied as potential covariates.

\section{Data Analysis}

Linkage equilibrium was tested according to HardyWeinberg's law by Chi-Square test for deviation from Hardy-Weinberg Equilibrium.

Comparability of sex for the three Lifetime suicidal behavior types was tested by Chi-square-test. Comparability of age at onset and for duration of illness was tested by OneWay ANOVA-test.

Testing of $2 \times 3$ tables was performed by Kruskal-Wallis test and testing for trends in $2 \times 3$ tables was performed by Armitage test for trend. The $2 \times 2$ matrix was tested by Chisquare-test. Logistic regression was applied to adjust for covariates.

We used a significance level at 0.05 , and in general, testing was 2 -sided. The calculations were performed by SPSS, version 16.

\section{Ethics}

The study was approved by the Danish Scientific-Ethical Committees and the Danish Data Protection Agency. All patients had given written informed consent prior to inclusion into the project.

\section{RESULTS}

Data were derived from 350 patients. Table 1 shows data on lifetime suicidal behavior types and original genotypes as well as functional genotypes. The distribution in Type 2 versus Type 1 was not deviant from Hardy-Weinberg equilibrium $(p=0.18)$, nor the distribution in Type 3 versus Type $1(\mathrm{p}=0.59)$.

Table 2 shows baseline distribution according to lifetime suicidal behavior types and genotypes (functional), sex, age at onset and duration of illness. For sex differences the distribution related to suicidal types was not significant by Chi-square $(p=0.43)$. For age at onset the distribution was tested with One-Way ANOVA-test and found significant $(\mathrm{p}=$ 
Table 1. Suicidality Type and Original Data on Genotypes

\begin{tabular}{|c|c|c|c|c|}
\hline \multirow{2}{*}{$\begin{array}{l}\text { Functional } \\
\text { Genotypes }\end{array}$} & \multirow{2}{*}{ Genotypes } & \multicolumn{3}{|c|}{ Lifetime Suicidal Behavior } \\
\hline & & Type 1: No Suicidal Behavior & $\begin{array}{l}\text { Type 2: Non-Violent/ } \\
\text { Non-Determinant Suicidal Behavior }\end{array}$ & $\begin{array}{c}\text { Type3: Violent/Determinant } \\
\text { Behavior }\end{array}$ \\
\hline \multirow{3}{*}{ SS } & SS & 29 & 18 & 9 \\
\hline & SLg & 13 & 5 & 2 \\
\hline & $\operatorname{LgLg}$ & 1 & 1 & 0 \\
\hline \multirow{2}{*}{ SL } & SLa & 97 & 56 & 11 \\
\hline & $\mathrm{LgLa}$ & 15 & 13 & 2 \\
\hline \multirow{2}{*}{$\mathrm{LL}$} & LaLa & 44 & 25 & 8 \\
\hline & LaL21 & 1 & 0 & 0 \\
\hline
\end{tabular}

0.047). Pair wise testing showed significant difference between Type 1 and Type $2(p=0.001)$, while Type 1 versus Type 3 only differed marginally $(p=0.06)$. Type 2 and 3 had exactly equal mean of age at onset. Duration of illness was tested with One-Way ANOVA-test and found not significant $(\mathrm{p}=0.28)$.

Calculations for genotypes and Lifetime suicidal behavior Type 2 versus Type 1: Kruskal-Wallis test for this $2 \times 3$ table was not significant $(\mathrm{p}=0.91)$, nor was Armitage test for trend $(\mathrm{p}=0.98)$. Calculations for Type 3 versus Type 1: Kruskal-Wallis test for this $2 \times 3$ table was not significant $(\mathrm{p}=0.21)$, nor was Armitage test for trend $(\mathrm{p}=0.44)$. Both these calculations were repeated through logistic regression with suicidal type as dependent variable and genotypes as independent variable and age-at-onset as a covariate. This only changed the results marginally.

We amalgamated genotypes and Lifetime suicidal behavior types in order to gain statistical power. In a $2 \times 2$ matrix the SS genotype was tested versus SL plus LL and Lifetime suicidal behavior Type 3 versus Types 1 plus 2 . In this way the difference was not significant $(\mathrm{p}=0.08)$. This testing was repeated through logistic regression with suicidal type as dependent variable and genotypes as independent variable and age-at-onset as a covariate. This only changed the results marginally.

\section{DISCUSSION}

As the duration of illness was high, and the suicidal behavior among schizophrenic patients mostly occurs in the first years of illness, we considered our concept and patient recruitment a strong basis for the study. However, a methodological concern is the completeness of hospital records as a tool of assessing lifetime suicidal behavior. It is possible that information about earlier suicide attempts may have been missed over the years, and that the use of all available current hospital records could have resulted in under-ascertainment of lifetime suicidal behavior. However, this possibility of misclassification of the outcome would be independent of the serotonin genotypes and would therefore not bias our findings. Other studies [21] have used interviews of patients to examine occurrence of attempted suicide and found that approximately one third of persons with schizophrenia or related disorder had attempted suicide. The proportion with any suicidal behavior throughout lifetime was higher in our sample, and we believe that differences in methods of assessments and sample selection characteristics provide likely explanations for this difference.

Conceptually, the phenotype under study is non-fatal suicidal conduct in patients with a diagnosis of schizophrenia. The study does not include individuals who committed suicide. It could be argued that those who actually commit suicide represent an extreme phenotype of

Table 2. Suicidality Types and Independent Variables

\begin{tabular}{|c|c|c|c|c|}
\hline \multirow{2}{*}{$\begin{array}{c}\text { Independent } \\
\text { Variables }\end{array}$} & $\begin{array}{c}\text { Type 1:Non Suicidal } \\
\text { Behavior (\%) }\end{array}$ & $\begin{array}{c}\text { Type 2:Non-Violent/Non-Determinant } \\
\text { Suicidal Behavior (\%) }\end{array}$ & $\begin{array}{c}\text { Type3: Violent/Determinant } \\
\text { Behavior (\%) }\end{array}$ \\
\cline { 3 - 6 } & SS & $43(21)$ & $24(20)$ & $11(34)$ \\
\cline { 2 - 5 } Genotype & SL & $112(56)$ & $69(59)$ & $13(41)$ \\
\cline { 2 - 5 } & LL & $45(23)$ & $25(21)$ & $8(25)$ \\
\hline \multirow{2}{*}{ Sex } & Male & $115(58)$ & $59(50)$ & $18(56)$ \\
\cline { 2 - 5 } & Female & $85(42)$ & $59(50)$ & $14(44)$ \\
\hline \multirow{2}{*}{ Age at Onset (SD) } & $28.56(\mathrm{SD} 10.24)$ & $24.80(\mathrm{SD} 7.36)$ & $24.81(\mathrm{SD} 11.48)$ \\
\hline \multicolumn{2}{|c|}{ Duration (SD) } & $13.63($ SD 9.85) & $15.13(\mathrm{SD} 10.08)$ & $15.79(\mathrm{SD} 10.08)$ \\
\hline
\end{tabular}


suicidal conduct of the violent/determinant type. However it is possible that these potential participants could add a slight effect, if they were included.

We think that our study with this enriched design (cases and controls from the same diagnostic group) had a reasonable power to detect a relevant difference in suicidal behavior risk genotype. Generally, we found the lifetime suicidal behavior types comparable. The finding that lower age at onset carries higher risk for suicidal behavior is wellknown, but adjustment for this did not change the overall results. Bayle et al. reported an association between violent suicidal behavior in 185 schizophrenic patients carrying the SS genotype [5]. We could not confirm this finding in our study with 350 schizophrenic patients.

\section{ACKNOWLEDGEMENT}

The study was supported by Psychiatric Centre Amager, Copenhagen University Hospital. Financial interests: None

\section{REFERENCES}

[1] Tanney BL. Psychiatric Diagnoses and Suicidal Acts. In: Maris RW, Berman AL, Sylverman MM, Eds. New York: The Guilford Press 2000; pp. 311-41.

[2] Rossau CD, Mortensen PB. Risk factors for suicide in patients with schizophrenia: nested case-control study. Br J Psychiatry 1997; 171: 355-9.

[3] Heila H, Lönnquist J. The clinical epidemiology of suicide in schizophrenia. In: Murray RM, Jones RM, Susser E, Van Os J, Eds. The Epidemiology of Schizophrenia. Cambridge: Cambridge University Press 2003; pp. 288-316.

[4] Asberg M, Traskman L, Thoren P. 5-HIAA in the cerebrospinal fluid. A biochemical suicide predictor? Arch Gen Psychiatry 1976; 33(10): 1193-7.

[5] Bayle FJ, Leroy S, Gourion D, et al. 5HTTLPR polymorphism in schizophrenic patients: further support for association with violent suicide attempts. Am J Med Genet B Neuropsychiatr Genet 2003; 119(1): 13-7.

[6] De Luca V, Zai G, Tharmalingam S, de BA, Wong G, Kennedy JL. Association study between the novel functional polymorphism of the serotonin transporter gene and suicidal behaviour in schizophrenia. Eur Neuropsychopharmacol 2006; 16(4): 268-71.

[7] Bondy B, Erfurth A, de JS, Kruger M, Meyer H. Possible association of the short allele of the serotonin transporter promoter gene polymorphism (5-HTTLPR) with violent suicide. Mol Psychiatry 2000; 5(2): 193-5.

[8] Courtet P, Baud P, Abbar M, et al. Association between violent suicidal behavior and the low activity allele of the serotonin transporter gene. Mol Psychiatry 2001; 6(3): 338-41.

[9] Turecki G, Zhu Z, Tzenova J, et al. TPH and suicidal behavior: a study in suicide completers. Mol Psychiatry 2001; 6(1): 98-102.

[10] Purselle DC, Nemeroff CB. Serotonin transporter: a potential substrate in the biology of suicide. Neuropsychopharmacology 2003; 28(4): 613-9.

[11] Mann JJ. Role of the serotonergic system in the pathogenesis of major depression and suicidal behavior. Neuropsychopharmacology 1999; 21(2 Suppl): 99S-105S.

[12] Li D, He L. Meta-analysis supports association between serotonin transporter (5-HTT) and suicidal behavior. Mol Psychiatry 2007; 12(1): $47-54$

[13] Chong SA, Lee WL, Tan CH, Tay AH, Chan AO, Tan EC. Attempted suicide and polymorphism of the serotonin transporter gene in Chinese patients with schizophrenia. Psychiatry Res 2000; 97(2-3): 101-6.

[14] Nakamura M, Ueno S, Sano A, Tanabe H. The human serotonin transporter gene linked polymorphism (5-HTTLPR) shows ten novel allelic variants. Mol Psychiatry 2000; 5(1): 32-8.

[15] Kraft JB, Slager SL, McGrath PJ, Hamilton SP. Sequence analysis of the serotonin transporter and associations with antidepressant response. Biol Psychiatry 2005; 58(5): 374-81.

[16] Wendland JR, Martin BJ, Kruse MR, Lesch KP, Murphy DL. Simultaneous genotyping of four functional loci of human SLC6A4, with a reappraisal of 5-HTTLPR and rs25531. Mol Psychiatry 2006; 11(3): 224-6.

[17] Jakobsen KD, Frederiksen JN, Hansen T, Jansson LB, Parnas J, Werge T. Reliability of clinical ICD-10 schizophrenia diagnoses. Nord J Psychiatry 2005; 59(3): 209-12.

[18] van Heeringen C. Epidemiological aspects of attempted suicide. A case-control study in Gent, Belgium. Crisis 1994; 15(3): 116-22.

[19] Rasmussen HB, Werge TM. Novel procedure for genotyping of the human serotonin transporter gene-linked polymorphic region (5HTTLPR)--a region with a high level of allele diversity. Psychiatr Genet 2007; 17(5): 287-91.

[20] Zalsman G, Huang YY, Oquendo MA, et al. Association of a triallelic serotonin transporter gene promoter region (5-HTTLPR) polymorphism with stressful life events and severity of depression. Am J Psychiatry 2006; 163(9): 1588-93.

[21] Harkavy-Friedman JM, Restifo K, Malaspina D, et al. Suicidal behavior in schizophrenia: characteristics of individuals who had and had not attempted suicide. Am J Psychiatry 1999; 156(8):12768 .

This is an open access article licensed under the terms of the Creative Commons Attribution Non-Commercial License (http://creativecommons.org/licenses/by$\mathrm{nc} / 3.0 /$ ) which permits unrestricted, non-commercial use, distribution and reproduction in any medium, provided the work is properly cited. 